\title{
LA BATALLA DE BALTARGA EN EL JOC DE LA POLÍTICA COMTAL DEL SEGLE X: LA MORT D'ERMENGOL D'OSONA I LA SUCCESSIÓ DEL COMTAT D’URGELL
}

\author{
THE BATTLE OF BALTARGA IN TENTH-CENTURY COUNTY POLITICS: \\ THE DEATH OF ERMENGOL OF OSONA AND THE SUCCESSION \\ TO THE COUNTY OF URGELL
}

\author{
OLIVER VERGÉS PONS \\ Institut d'Estudis Medievals (IEM - UAB) \\ http://orcid.org/0000-0003-4921-722X
}

\begin{abstract}
Resum: La mort del comte Ermengol d'Osona a la batalla de Baltarga (c. 940) ha estat interpretada de dues maneres totalment oposades. Per a alguns, aquesta batalla va consistir en una topada entre catalans i nòmades hongaresos, mentre que per a d'altres fou un enfrontament entre les principals cases comtals catalanes. En aquest article abordarem la principal historiografia sobre el tema i situarem l'enfrontament de Baltarga al centre del joc de la política comtal catalana de mitjan segle X, rebutjant així les tesis que parlen d'un xoc contra hordes hongareses. Des del primer terç de la desena centúria diverses tensions van enfrontar les cases comtals de Barcelona i Cerdanya, unes tensions que van derivar en un enfrontament armat a la dècada del 940 per dirimir la successió del comtat d'Urgell i l'hegemonia als comtats catalans entre els fills i néts de Guifré el Pelós.
\end{abstract}

Paraules clau: política comtal; successió Urgell; batalla Baltarga; hegemonia comtats catalans; Ermengol d'Osona.

Abstract: The death of Count Ermengol of Osona at the Battle of Baltarga (c. 940) has been understood in two very different ways. According to some, this battle was a clash between Catalans and Hungarian nomads, but others interpret it as a confrontation between the ruling families of the main Catalan counties. In this paper, we will consider the main historiographical studies on the topic and place the encounter at Baltaraga at the core of the struggles in Catalan county politics in the mid-10th century, thus rejecting the thesis that proposes a skirmish with Hungarian hordes. From the first third of the 10th century, different tensions led to the confrontation of the comital houses of Barcelona and Cerdanya, which resulted in an armed conflict in the 940's in order to settle the succession to the county of Urgell and the hegemony of the Catalan counties among the sons and grandsons of Wifred the Hairy.

Keywords: county politics; succession to Urgell; battle of Baltaraga; hegemony in Catalan counties; Ermengol of Osona.

\section{SUMARI}

1. Introducció.- 2. Els dos principals relats de la mort d'Ermengol d'Osona i de la batalla de Baltarga.- 3. Una batalla entre forces comtals i hordes hongareses? Les tesis de Benet a debat.- 4. Els hongaresos a terres catalanes.- 5. Els comtats mig segle després de la mort del Pelós.- 6. Sunifred II d'Urgell, el tercer en discòrdia.- 7. De Besalú a Urgell (920-940).- 8. Ermengol d'Osona, primogènit de Sunyer I, comte d'Urgell.9. La batalla de Baltarga, les usurpacions sobre Sant Joan de les Abadesses i la incursió a la Vall de Lord (941-947).- 10. La fi del conflicte.- 11. L'epitafi d'Ermengol d'Osona i el retir de Sunyer I.- 12. Conclusió.- 13. Bibliografia citada.

Cómo citar este artículo: Vergés Pons, Oliver (2018), La batalla de Baltarga en el joc de la política comtal del segle X: la mort d'Ermengol d'Osona i la successió del comtat d'Urgell, "Anuario de Estudios Medievales" 48/2, pp. 901-923. https://doi.org/10.3989/aem.2018.48.2.13

Copyright: (c) 2018 CSIC. This is an open-access article distributed under the terms of the Creative Commons Attribution 4.0 International (CC BY 4.0) License. 


\section{INTRODUCCIÓ ${ }^{1}$}

A principis dels anys quaranta de la desena centúria, un jove comte anomenat Ermengol moria a Baltarga, al comtat de Cerdanya. Fill de Sunyer I de Barcelona i d'una dama anomenada Riquilda, Ermengol havia començat a actuar com a comte associat en terres osonenques cap a finals de la dècada de 930. Per desgràcia seva, però, va topar amb la mort en plena joventut, encara en vida del seu pare. Les Gesta Comitum Barchinonensium esmenten només succintament el seu traspàs, dient tan sols que Ermengol, germà del futur comte Borrell II de Barcelona-Urgell, va finar a la localitat pirinenca de Baltarga a causa d'un conflicte armat. Cap referència sobre la causa de la seva mort. Cap notícia sobre les raons que havien dut el comte d'Osona a endinsar-se a les terres del seu cosí Sunifred II de Cerdanya. Més de mil anys després, els nostres historiadors parlen de la batalla de Baltarga, una contesa bèl-lica que s'hauria produït l'any 942 i de la qual no se sap pràcticament res. En general, tothom és del parer que el comte Ermengol d'Osona va morir en aquesta suposada batalla. Tanmateix, la manca d'informació ha creat opinions divergents entre els historiadors a l'hora d'identificar els possibles contendents enfrontats en el xoc en qüestió $i$, en conseqüència, a l'hora d'assenyalar les causes del conflicte que va suposar la mort d'Ermengol en aquesta localitat cerdana.

A parer nostre, cal una revisió d'ambdues qüestions que permeti aportar nova llum sobre la mort del comte d'Osona i sobre la dita batalla. El primer pas, evidentment, passa per dur a terme un estat de la qüestió seguint els principals (i pocs) autors que han abordat el tema en els últims anys. Serà a partir d'aquest punt que podrem revisar les fonts i confirmar, matisar o replantejar uns fets que creiem que, ara per ara, ens són força desconeguts. Tant si es tracta d'un conflicte entre exèrcits dels comtats catalans i tropes hongareses com si es tracta d'un conflicte intern de la política comtal catalana, l'estudi d'aquest episodi ens haurà de servir per aprofundir en la història comtal del segle $X$, una història que encara hem d'acabar d'escriure.

\section{ELS DOS PRINCIPALS RELATS DE LA MORT D'ERMENGOL D'OSONA I DE LA BATALLA DE BALTARGA}

Les Gesta Comitum Barchinonensium expliquen, en parlar del comte Borrell II, que Ermengaudus vero frater eius, apud Baltargam bello interfectus,

\footnotetext{
${ }^{1}$ A la meva àvia, Montserrat Mill Pallarès (1923- 2014), nascuda i criada en aquesta estimada terra pirinenca. Vola, ocell de bosc.
} 
sine filio obiit ${ }^{2}$. Aquesta concisa referència i la data de la seva mort, ocorreguda el dia 21 o 22 d'agost segons els necrologis de Ripoll, Girona i Vic que malauradament no ens informen de l'any en què es produí el succés, és tot el que sabem de la mort del comte d'Osona. Pròsper de Bofarull, en la seva obra Los Condes de Barcelona vindicados va ser un dels primers autors a parlar del tema, i va arribar a la conclusió que el plançó de Sunyer I i Riquilda murió indudablemente asesinado ó en accion de guerra ${ }^{3}$. Amb tot, l'autor no va més enllà i no s'aventura a teoritzar sobre quina acció de guerra hauria implicat tan fatals conseqüències. Bofarull, en aquell moment, segurament desconeixia la informació que aportaven les Gesta, d'aquí que no pogués afegir comentaris a la notícia.

A la dècada dels setanta del segle XX, Miquel Coll i Alentorn va relacionar la mort del comte amb les friccions existents entre els casals de Barcelona i Cerdanya, dirigits per Sunyer I i Sunifred II, respectivament, per raó de diversos dominis fronterers dels seus comtats al Ripollès ${ }^{4}$. La hipòtesi fou recollida per Josep Maria Salrach, qui l'any 1973 la reproduïa en un article sobre la revolta patida pel comte Guifré de Besalú l'any $957^{5}$. Ambdós autors estan convençuts que les ambicions del comte Sunyer I de Barcelona l'haurien portat a voler annexionar-se alguns territoris que eren a mans del casal de Cerdanya, cosa que hauria degenerat en un enfrontament obert acabat tràgicament a Baltarga quan el fill de Sunyer, Ermengol, recentment associat al poder en terres osonenques, hauria penetrat a Cerdanya i s'hauria enfrontat al seu cosí Sunifred II.

Nou anys més tard, Albert Benet va publicar un article en què estudiava les incursions hongareses que van patir els comtats catalans a la primera meitat de la desena centúria ${ }^{6}$. En aquella publicació, l'historiador de la Catalunya central parlava dels atacs de les hordes hongareses que havien afectat les comarques gironines i que havien acabat amb un setge a la ciutat musulmana de Lleida. Immediatament després, ell mateix publicava un breu article, gairebé una nota, en què defensava que a la batalla de Baltarga de l'any 942, catalans i hongaresos s'havien enfrontat, quan aquests últims es batien en retirada del setge de Lleida, un enfrontament que hauria tingut com a tràgica consequiència la mort del comte Ermengol d'Osona ${ }^{7}$.

A dia d'avui les tesis de Benet són les més comunament acceptades, $\mathrm{i}$ en diverses publicacions en què es parla de la batalla de Baltarga o de la mort

\footnotetext{
${ }^{2}$ Cingolani 2012, p. 127

${ }^{3}$ Bofarull 1836, p. 114.

${ }^{4}$ Coll 1992, p. 196.

${ }^{5}$ Salrach 1973, p. 7.

${ }^{6}$ Benet 1982a.

${ }^{7}$ Benet 1982b.
} 
d'Ermengol d'Osona hom associa ambdós fets amb les incursions hongareses del $942^{8}$. Però no tothom és d'aquest parer. Coll, en una nova publicació posterior a la de Benet, reafirmava la seva postura adduint que si un príncep cristià hagués mort lluitant contra pagans hongaresos destructors d'esglésies se l'hauria recordat i lloat molt més que amb una escadussera nota a les Ges$t a^{9}$. El mateix autor diu, a més, que els versos que l'abat Oliba dedicà al difunt Ermengol, versos sobre els quals tornarem més endavant, expressen més un record dolorós que no pas la glòria d'un fidel defensor de la Cristiandat. Més recentment, Joan Blasi ha recuperat les tesis de Coll i ha considerat que el conflicte ha de ser entès en clau interna de la política comtal catalana ${ }^{10}$.

Ens trobem, per tant, davant de dos relats totalment contraposats. És evident, per tant, que un dels dos no explica satisfactòriament els motius i les causes que van originar la contesa. A parer nostre, i malgrat l'opinió majoritària de la historiografia catalana, creiem que cal recuperar les tesis de Coll i Salrach dels anys setanta. Pensem que la seva hipòtesi és més fidel a la realitat, amb diversos matisos, com esperem poder demostrar al llarg d'aquest article. Amb tot, no podem limitar-nos a descartar arbitràriament les tesis de Benet, unes tesis que comentarem a continuació i exposarem els motius que ens porten a deixar-les de banda.

\section{UNA BATALLA ENTRE FORCES COMTALS I HORDES HONGARESES? LES TESIS DE BENET A DEBAT}

Cal advertir, d'antuvi, que en cap moment posem en dubte que hordes hongareses vagin travessar els comtats catalans durant la primera meitat del segle X. Tant les fonts musulmanes com les cristianes, tot i la inexactitud cronològica d'aquestes últimes, ho testimonien. Tanmateix, creiem que la manca de documentació més concreta fa difícil acceptar la precisió del relat històric de Benet, un relat que creiem que empra les fonts d'una manera excessivament arbitrària.

Josep Maria Millàs i Vallicrosa, l'any 1963, va publicar un dels primers estudis referents a les invasions hongareses a Catalunya, fins aquell moment un tema força desconegut, associant la destrucció de l'església de Santa Coloma de Farners, que per nefandis paganis fuit destructa, que dicunt

\footnotetext{
${ }^{8}$ Per citar alguns exemples: Pladevall 1995, p. 35; Sabaté 2009, p. 125; Cingolani 2012, p. 127.

${ }^{9}$ Coll 1992, p. 196.

${ }^{10}$ Blasi 1999, p. 140.
} 
Ungulis, amb el pas d'aquestes hordes ${ }^{11}$. L'expert semitista, nascut justament a la localitat selvatana a la qual pertanyia l'església destruïda, va adonar-se que aquells pagans que citava l'acta de consagració de la reconstruïda basílica (any 950) no eren sarraïns, els quals apareixen recurrentment a les consagracions catalanes, sinó hongaresos. Seguint aquesta línia, Millàs citava d'altres exemples d'esglésies de les comarques gironines destruïdes per aquelles dates que podrien haver sucumbit a mans dels mateixos hongaresos, com ara el monestir de Sant Esteve de Banyoles. Per acabar d'arrodonir el seu article, a Millàs li van mancar els textos àrabs que fan referència al setge de Lleida de l'estiu del 942 i que aporten d'altres notícies interessants ${ }^{12}$. Si bé és cert que l'acta de consagració de Santa Coloma de Farners i d'altres actes de consagració contemporànies, aquestes últimes més indirectament, parlen de destruccions que podem associar als hongaresos, la majoria en terres gironines, creiem que Benet va anar massa enllà $i$ va emprar arbitràriament altres actes similars de mitjan segle $\mathrm{X}$ per tal de demostrar la ruta seguida pels hongaresos a Catalunya.

En concret, va utilitzar diverses consagracions que li permetien resseguir el pas de les hordes nòmades que, després d'abandonar Lleida i prendre el camí cap a la vall del Segre, els hauria dut a Baltarga, on el 21 d'agost del 942 es produí l'encontre entre les tropes hongareses i les catalanes i ultrapirinenques ${ }^{13}$. En aquest sentit, parla de la possible destrucció de Santa Maria de Solsona, Sant Cristòfor de Salinoves i Sant Feliu de Castellciutat, al comtat d'Urgell ${ }^{14}$. El problema és que les actes de consagració d'aquestes esglésies no permeten, ni de bon tros, afirmar que vagin ser destruïdes pels hongaresos, bàsicament perquè moltes actes i altres documents d'aquest període afirmen que tal o qual església va ser destruïda, i fins i tot algunes afirmen que van ser destruïdes per pagans, però no s'indica ni quan va passar ni qui va ser l'autor material de la destrucció. Molt sovint, afirmacions d'aquestes característiques amaguen la voluntat de justificar la possessió o el dret d'una determinada institució eclesiàstica sobre un espai concret.

L'església de Santa Maria de Solsona va ser consagrada l'any 977, trenta-cinc anys després del setge hongarès de Lleida ${ }^{15}$. En la dotalia en qüestió no es parla de cap destrucció i suposem que la consagració es deu a l'edificació d'un nou temple o a la remodelació d'un d'antic, no pas a la reconstrucció posterior a un atac no documentat. Per la seva banda, Sant Cristòfor

\footnotetext{
${ }^{11}$ Millàs 1963,p. 74.

${ }^{12}$ Bramon 2000, pp. 302-308.

${ }^{13}$ Benet 1982b, p. 640 .

${ }^{14}$ Benet 1982a, p. 572; 1982b, p. 640.

${ }^{15}$ Baraut 1986, doc. 33.
} 
de Salinoves, qui fuit antiquitus constituta et propter infestationem paganorum fuit destructa, va ser consagrada l' any $949^{16}$. Qui eren aquests pagans que la van destruir? Per a Benet podrien haver estat les hordes hongareses, i no ho podem descartar taxativament, ja que la informació que tenim és tan sols aquesta. Tanmateix, diversos elements ens porten a contradir la seva hipòtesi. D'una banda, Salinoves, al segle X, es trobava al sud del comtat d'Urgell, prop de la frontera amb el califat de Còrdova. De fet, era a una desena de quilòmetres de les documentades fortaleses musulmanes de Meià i Montmagastre. Seria si més no curiós que després de dos segles de presència musulmana a la península ibèrica haguessin estat justament els hongaresos, l'estiu del 942, els destructors de Sant Cristòfor de Salinoves. D'altra banda, aquest document especifica que la (re)construcció fou encapçalada pels abats Gulfí i Melandre de Santa Cecília d'Elins, documentats en el càrrec entre el 932 i el 955. Per tant, aquesta reconstrucció podria haver començat l'any 932, una dècada abans de l'arribada dels hongaresos a Lleida. La tercera església urgellenca que menciona Benet és Sant Feliu de Castellciutat, assaltada pels hongaresos en el seu pas per la vall del Segre de retorn de la seva expedició que arribà fins a Lleida ${ }^{17}$. Aquesta església fou consagrada l'any 952 pel bisbe Guisad II i en cap moment es fa referència a una destrucció prèvia ${ }^{18}$. És possible que fos destruïda pels hongaresos? Doncs possible ho és, tanmateix, si fos així, creiem que les proves d'aquesta destrucció i de les de Solsona i Salinoves serien més evidents i contundents i no meres especulacions.

Una altra qüestió conflictiva és la data en què es va produir la batalla de Baltarga. El comte Ermengol d'Osona, segons els necrologis de Girona, Ripoll i Vic, va morir el dia 21 o el 22 d'agost, sense que s'especifiqui de quin any. Segons el gironí, la mort del comte s'hauria produït el dia 21 (XII kalendas septembris) ${ }^{19}$, mentre que els de Vic i Ripoll diuen que aquesta es va produir el 22 (XI kalendas septembris) ${ }^{20}$. L'últim document que ens parla d'aquest comte actuant en vida data del 23 d'agost del 939 i consta com a traspassat el 6 de setembre de $943^{21}$. Per tant, el comte Ermengol pogué morir a Baltarga el 21 o 22 d'agost de 940, 941, 942 o 943 . Benet descarta el 943 perquè considera que quinze dies són poques jornades entre una mort, la del comte, i una donació pro anima feta per al difunt, en aquest cas una donació feta pel comte Sunyer I a Santa Maria de Ripoll (6 de setembre de 943). És

\footnotetext{
${ }^{16}$ Ibidem, doc. 32.

${ }^{17}$ Benet 1982b, p. 640.

${ }^{18}$ Baraut 1986, doc. 34.

${ }^{19}$ Flórez 1819, p. 495.

${ }^{20}$ Flórez 1774, p. 322; Junyent 1962, p. 223.

${ }^{21}$ Ordeig 1999, doc. 464 i 535, respectivament.
} 
cert que quinze dies són poc temps, però entre Baltarga i Ripoll la distància és relativament petita i sabem que el comte Ermengol d'Osona va ser sepultat en aquest monestir ${ }^{22}$. A tall d'exemple, encara que una mica posterior, el 14 d'octubre de 1058, a Santa Maria de la Seu d'Urgell, s'hi va fer la publicació sacramental del testament de l'urgellenc Guitard, el qual havia mort tan sols dos dies abans ${ }^{23}$. No seria impossible, doncs, que en dues setmanes el fèretre hagués arribat al cenobi pirinenc, hagués rebut sepultura i el pare del difunt hagués fet una donació per l'ànima del seu fill. Reforça també la hipòtesi del 943 el fet que el desembre d'aquell any la comtessa Riquilda va fer també una donació al monestir de Ripoll per l'ànima del seu plançó ${ }^{24}$. Però el problema va més enllà perquè Benet únicament descarta el 943 com a any de mort del comte i no pas els anys 940 i 941 . Considera que la darrera notícia d'Ermengol vivent és del 21 d'agost del $942^{25}$. En aquest punt, tanmateix, no és coherent amb les proves documentals, ja que com hem esmentat més amunt l'últim document que parla d'Ermengol d'Osona en vida data del 23 d'agost del 939. La data de 21 d'agost de 942 sembla simplement un acomodació entre el dia que va morir el comte i l'any en què els hongaresos van assetjar Lleida, sense que cap prova indiqui que aquell dia i aquell any Ermengol d'Osona es trobava a Baltarga plantant cara als hongaresos. Així doncs, ara mateix, cap prova presentada per Benet ni cap altre document que coneguem permeten dir en quin any, entre el 940 i el 943, va morir a Baltarga el fill de Sunyer I.

Finalment cal esmentar un parell de qüestions que, si bé no són fonamentals per a les tesis que defensa Benet sí que han ajudat a elaborar aquest relat de la batalla de Baltarga i que creiem que cal comentar. D'una banda, Benet diu que els catalans van esperar els hongaresos a Balltarga, on el riu s'engorja davant el castell de Sant Martí i el terreny és idoni per atacar un exèrcit basat en una cavalleria lleugera ${ }^{26}$. En aquesta afirmació l'autor comet un error geogràfic, ja que Sant Martí dels Castells, on el riu s'engorja, es troba a uns vuit quilòmetres en línia recta de Baltarga. Justament a Baltarga, a la Batllia cerdana, es comença a obrir la plana i queden enrere els engorjats del Baridà. Es tracta d'un petit error però important perquè el desenvolupament d'una batalla d'aquestes característiques no hauria estat el mateix en un tipus de terreny que en un altre. Per acabar de reblar el clau, Benet defensava en el seu primer article que cap de les dades disponibles de la part cristiana

\footnotetext{
${ }^{22}$ Ho sabem a través d'un afegit fet pel glossador en el text de les Gesta (Cingolani 2012, p. 127).

${ }^{23}$ Baraut 1983, doc. 710.

${ }^{24}$ Ordeig 1999, doc. 539.

${ }^{25}$ Benet 1982b, p. 639.

${ }^{26}$ Ibidem, p. 640.
} 
no permeten pensar que [els hongaresos] penetressin per la vall del Segre, ja que aquests eren enemics de les valls tancades on s'exposaven molt a quedar encerclats per l'enemic, al mateix temps que el factor sorpresa aviat desapareixia $^{27}$. És cert que l'opinió d'un historiador canvia a mesura que el seu coneixement augmenta i la seva capacitat interpretativa madura, però en aquest cas es tracta d'un canvi d'argumentació que passa del blanc al negre sense cap mena de justificació.

Al nostre entendre, Albert Benet va adaptar diversos fets, que realment es van produir, i va crear un relat fictici que avui coneixem com la batalla de Baltarga entre catalans i hongaresos el 942, una contesa entre tropes nòmades que si en algun moment es va produir creiem que no hauria tingut lloc a Baltarga i, per tant, tampoc hauria suposat la mort del comte Ermengol d'Osona.

\section{ELS HONGARESOS A TERRES CATALANES}

Rebutjar les tesis de Benet sobre la batalla de Baltarga del 942 no implica pas negar les incursions hongareses a terres catalanes durant la primera meitat del segle X. Malgrat que no és l'objectiu principal d'aquesta publicació, creiem oportú fer un breu esment de la informació que ens aporten les fonts al voltant d'aquesta qüestió. Com comentàvem en l'apartat anterior, Josep Maria Millàs va fer el primer estudi sobre el tema relacionant la destrucció de l'església de Santa Coloma de Farners amb un atac hongarès que hauria afectat la Septimània cap al 924 i també terres gironines. Aquesta és l'única font cristiana que permet parlar d'atacs als comtats catalans, si bé, com hem exposat, Millàs i Benet posteriorment han relacionat altres consagracions d'esglésies de mitjan segle $\mathrm{X}$ amb el pas d'aquestes hordes. En alguns casos, cap al comtat de Girona o el de Besalú, segurament encerten, en d'altres, com en els casos ja esmentats, aquesta hipòtesi és força dubtosa i difícil de comprovar.

Les fonts més importants sobre aquests atacs provenen, sobretot, de textos d'historiadors àrabs que han arribat fins als nostres dies i que van ser recollits per Dolors Bramon ${ }^{28}$. Segons l'al-Muqtabis d'Ibn Hayyan, a l'estiu del 942 va arribar a la Frontera Superior un exèrcit hongarès (turk al text original i traduït per hongarès partint de les tesis de Millàs) provinent del país dels francs (balad al-Ifranga). Aquest exèrcit es mogué per les proximitats de Lleida pels volts del 7 de juliol de 942 i finalment posà setge a la ciutat durant vuit dies,

\footnotetext{
${ }^{27}$ Benet 1982a, p. 572.

${ }^{28}$ Bramon 2000, pp. 302-308.
} 
període durant el qual feren presoner el governador de Barbastre. No podent atacar la ciutat, al final es retiraren, frustrats, sense queviures ni ferratges, al seu campament $i$ marxaren per on havien vingut ${ }^{29}$. El mateix Ibn Hayyan informa que més tard els francs i els seus aliats de les nacions veïnes van derrotar els hongaresos infringint-los grans pèrdues ${ }^{30}$. És cert que a partir d'aquest últim fragment hom pot deduir que una coalició de forces catalanes va enfrontar-se i derrotà als hongaresos, però el terme franc en aquest moment i des de l'òptica musulmana tenia un sentit molt ampli i no podem afirmar categòricament si aquests francs eren homes dels comtats catalans o bé de l'interior del regne carolingi. A més, tampoc queda clar quan es va produir aquesta victòria, ja que en el fragment immediatament anterior l'historiador musulmà fa referència a l'arribada a Còrdova del capturat governador de Barbastre el 5 de gener del 943 i després notifica la victòria dels francs. De fet, en tot el fragment anterior parla del període comprès entre el 14 de setembre de 942 i el 5 de gener del 943 . Si l'autor segueix en la seva exposició un ordre cronològic, com sembla que fa, la suposada batalla entre catalans i hongaresos hauria de ser posterior a aquestes dates i, per tant, s'hauria produït el 21 o el 22 d'agost del 943. Acceptar això, però, tampoc sembla possible, ja que implicaria que entre el juliol del 942 i l'agost de l'any següent un exèrcit hongarès hauria deambulat per terres catalanes i per la Frontera Superior sense que en tinguem cap notícia.

Com podem veure, les dades que tenim sobre el pas dels hongaresos pels comtats catalans són d'allò més escadusseres i tan sols permeten afirmar tres coses. En primer lloc, que els hongaresos en algun moment de la primera meitat del segle X van atacar Santa Coloma de Farners i d'altres localitats veïnes. En segon lloc, que un atac hongarès va dirigir-se a Lleida el juliol del 942 i que va posar setge durant vuit dies a la ciutat. I, finalment, que en algun moment posterior a aquest setge es va produir una topada entre un exèrcit franc i els seus aliats que van derrotar aquesta ràtzia. Ara per ara, per tant, se'ns fa difícil acceptar sense més que realment el 21 d'agost del 942 s'hagués produït una batalla a Baltarga entre catalans i hongaresos.

\section{ElS COMTATS MIG SEGLE DESPRÉS DE LA MORT DEL PELÓS}

La mort d'Ermengol d'Osona i la batalla de Baltarga es van produir arran de la conflictivitat entre els diversos successors del Pelós a Barcelona, a Cerdanya i a Urgell. El motiu de les tensions no era altre que l'hegemonia

\footnotetext{
${ }^{29}$ Ibidem, p. 303.

${ }^{30}$ Ibidem, p. 305.
} 
política en el si dels comtats. A la seva mort, Guifré I havia repartit els seus dominis de la manera següent: el bloc dels comtats de Barcelona, Osona i Girona va passar a mans de Guifré II (897-911), el qual, en morir sense descendència, va llegar-los al seu germà petit Sunyer (911-947), que estava sota la seva tutela; el comtat de Cerdanya va passar a Miró II, el qual a partir del 920 també va esdevenir comte de Besalú, i finalment, el comtat d'Urgell, antigament associat al de Cerdanya, va passar a mans de Sunifred II (897-c. 940) ${ }^{31}$.

Durant una trentena d'anys aproximadament, els principals comtats van ser governats pels fills de Guifré I amb aparent estabilitat. La cosa va canviar, tanmateix, a mesura que van haver de produir-se successions. Miró II de Cerdanya fou el primer a traspassar, si no comptem Guifré II, la successió del qual ja havia quedat establerta i consolidada. El problema era que els seus fills encara no estaven en edat de governar el 927 i la comtessa Ava va ocupar-se temporalment de la regència a l'espera que el primogènit, Sunifred, pogués actuar com a comte amb plenes facultats. Sembla que Sunyer I de Barcelona va aprofitar aquesta inestabilitat, com apunten Coll i Salrach, per guanyar terreny en territoris limítrofs d'ambdós comtats, com ara en zones del Ripollès i també al comtat de Besalú32. Malgrat que no puguem saberho del cert, Sunyer segurament era un home ambiciós que esperava governar de nou totes les antigues possessions paternes. De fet, ell era el més jove de tots els germans i per tant l'edat era un factor que podia jugar al seu favor. El problema era que des del tombant del segle $\mathrm{X}$ en els diversos comtats els seus germans s'havien consolidat poc o molt i era força difícil arrabassarlos les possessions. Al final, si bé Sunyer devia treure algun partit de les seves maniobres, els guanys no van ser els esperats.

És en el si d'aquesta conflictivitat que Coll i Salrach situen la batalla de Baltarga i la mort del comte d'Osona, com si es tractés d'un episodi més d'aquestes tensions. Tot i que som del parer que l'encerten en relacionar aquests fets amb tensions pròpies de la política comtal catalana, creiem que hi ha quelcom d'aquesta interpretació que trontolla. Ambdós autors consideren que Ermengol hauria penetrat a Cerdanya per afirmar la seva sobirania sobre la vall de Ripoll, i a Baltarga hauria topat amb les forces del seu cosí, Sunifred II de Cerdanya, ja plenament assentat en el càrrec comtal. La batalla hauria suposat la derrota i mort del jove comte osonenc. Ara bé, tenint en compte que l'acció d'Ermengol hauria estat instigada pel seu pare, per què haurien hagut d'esperar a la dècada dels quaranta per dur a terme aquesta maniobra? La regència d'Ava havia començat el 927 i la situació va perllongar-

\footnotetext{
${ }^{31}$ Salrach 1973, p. 4.

${ }^{32}$ Coll 1992, p. 196; Salrach 1973, p. 7.
} 
se fins aproximadament el 940. És relativament estrany que si realment Sunyer volia donar un cop d'efecte important s'esperés fins a la majoria d'edat dels seus nebots per fer-ho. Segons Coll, al desembre del 942 Sunyer hauria actuat contra possessions de Sant Joan de les Abadesses, la qual cosa hauria provocat el conflicte armat que s'hauria prorrogat, per raons climàtiques, fins a l'estiu següent ${ }^{33}$. Això, però, no respon el nostre interrogant, ja que si el que realment Sunyer buscava era l'enfrontament cos a cos i la invasió de la Cerdanya, esperar que els comtes d'aquell territori tinguessin un poder més estable i consolidat no era la decisió més encertada.

I una altra qüestió: si les tensions eren motivades pel domini de zones limítrofes d'Osona i Cerdanya al Ripollès, per què la contesa es va produir a Baltarga? Una penetració armada des dels nuclis barcelonins s'hauria produït justament per la vall de Ribes i hauria afectat, en primer terme, la banda totalment oposada de la plana cerdana (on actualment hi ha Das, Alp o Queixans). Coll diu que, si bé la ruta a través de la vall de Ribes no és descartable, segurament Ermengol va entrar a Cerdanya pel coll de Pendís, venint de l'alt Berguedà ${ }^{34}$. Aquesta ruta li serveix per explicar per què el conflicte es va produir a Baltarga, però és un camí que no té cap sentit per dues raons. La primera és que la zona de Berga estava sota la sobirania dels comtes de Cerdanya i, per tant, en situació d'hostilitat, no era una via segura si Ermengol volia atacar el cor del comtat de Cerdanya. Si hagués passat per l'alt Berguedà la batalla potser no s'hauria produït al nord del Cadí-Moixeró, sinó al sud. La segona, com ja hem esmentat, és que si el conflicte s'havia originat per dominis ripollesos, Ermengol no hauria fet aquesta marrada tan gran per entrar a Cerdanya pel Pendís, hauria seguit cap al nord amb l'enemic davant i els seus dominis a l'esquena, sense deixar les seves possessions desemparades a un possible (contra)atac dels seus cosins.

Creiem, per tant, que si bé la batalla va estar relacionada amb qüestions internes de la política comtal, les tesis de Coll i Salrach no expliquen satisfactòriament perquè va produir-se a principis dels anys quaranta del segle $\mathrm{X}$ i no abans, quan tindria més sentit, ni per què es va produir a Baltarga, un indret relativament allunyat de les zones en suposat conflicte i allunyat també de les vies lògiques de penetració a la Cerdanya des dels dominis barcelonins.

${ }^{33}$ Coll 1992, p. 196.

${ }^{34}$ Ibidem. 


\section{SUNIFRED II D'URGELL, EL TERCER EN DISCÒRDIA}

I quin paper va jugar Sunifred II d'Urgell en aquesta història? El cert és que les tensions entre els casals de Barcelona i Cerdanya no semblen haver pertorbat el comtat d'Urgell i Sunifred II segurament va mantenir-se'n al marge, com també ho féu el seu germà Radulf, que per aquelles dates era ja bisbe d'Urgell. El que sí que hem de negar categòricament és la idea que Sunifred hagués afavorit Sunyer pel fet d'haver-se esposat amb la filla d'aquest. En efecte, alguns historiadors han identificat Adelaida, comtessa d'Urgell, amb Adelaida Bonafilla, filla de Sunyer I i Riquilda i abadessa, a mitjan segle X, del monestir femení de Sant Joan de les Abadesses ${ }^{35}$. Aquesta filiació és del tot impossible, ja que l'any 907 Sunifred II i Adelaida ja actuaven conjuntament a terres urgellenques i en aquestes dates Sunyer I i Riquilda no s'havien ni esposat $^{36}$. Ara bé, el fet que el comte d'Urgell no intervingués en aquest conflicte no implica que no hi tingués cap protagonisme.

Tradicionalment s'ha dit que Sunifred II va traspassar, sense successor, l'any $948^{37}$. El càrrec comtal urgellenc va acabar recaient en Borrell II que, junt amb el seu germà Miró durant alguns anys, va governar els comtats de Barcelona, Girona, Osona i Urgell (948-993). Aquesta explicació, tanmateix, presenta diversos problemes, alguns dels quals ja han estat destacats en els últims anys ${ }^{38}$. El primer i fonamental és la data de traspàs de Sunifred II. Hom ha considerat que va viure, com a mínim, fins el 948 perquè en un document urgellenc, datat d'aquell any, s'exposava que el comte havia usurpat unes parròquies de la vall de Lord ${ }^{39}$. En contra d'aquesta interpretació es poden al·legar dues qüestions. D'una banda, en el capbreu del 948 es parla d'unes usurpacions, però no s'especifica quan es van produir i, per tant, podrien haver succeït perfectament una dècada abans. De l'altra, i al nostre entendre més important, a mitjan segle $\mathrm{X}$ als comtats catalans hi havia dos comtes homònims, Sunifred II d'Urgell i Sunifred II de Cerdanya i en el document no diu de quin dels dos es tracta. Més endavant tornarem sobre aquesta qüestió. L'últim document en què Sunifred II actua en vida data del 935 i l'any 941 la comtessa Adelaida ja actua sola ${ }^{40}$. Per tant, la mort de Sunifred s'hauria produït cap al 940 aproximadament i la comtessa vídua, durant un període indeterminat però breu, va actuar com a regent.

\footnotetext{
${ }^{35}$ Fluvià 1989, p. 120; Abadal 2011, p. 187; Sobrequés, Morales 2011, p. 27.

${ }^{36}$ Baraut 1979, doc. 65.

${ }^{37}$ Salrach 1973, p. 6; Sobrequés, Morales 2011, p. 30.

${ }^{38}$ Martí 2013,p. 84.

${ }^{39}$ Villanueva 1821 , ap. 13.

${ }^{40}$ Baraut 1979, doc. 96 i 100.
} 
La segona qüestió, derivada de la primera, rau a saber qui va actuar com a sobirà d'Urgell entre l'òbit de Sunifred i el govern de Borrell (c. 940948). Segons E. Baluze, l'any 944 Sunyer I actuava com a comte d'Urgell, tot i que en el moment en què aquest autor va escriure-ho hom creia que Sunyer havia succeït al seu pare Guifré a Urgell ${ }^{41}$. El cert és, però, que cap a l'any 944 la successió urgellenca, com veurem, sembla que havia estat guanyada per als interessos barcelonins després de la mort d'Ermengol d'Osona. Per tant, entre els anys 941 i 944 es va dirimir, en el si dels successors de Guifré el Pelós, qui havia d'esdevenir comte d'Urgell, una qüestió transcendental que sens dubte va marcar la política dels comtats catalans en aquells anys.

\section{De Besalú a URgell (920-940)}

Descartada la possibilitat que Sunyer I casés la seva filla Adelaida amb el seu germà Sunifred II d'Urgell, descartem també que la successió urgellenca hagués de recaure forçosament en els sobirans barcelonins en virtut d'aquest matrimoni. Però abans d'entrar a fons en la qüestió d'aquesta successió creiem oportú de remuntar-nos uns anys enrere, per referir-nos de nou als repartiments territorials a la mort de Guifré el Pelós. Per delegació de Guifré, el seu germà Radulf va governar el comtat de Besalú de manera privativa des de finals del segle IX fins ben entrat el segle X; per tant, fins després de la mort del seu germà. Besalú havia estat un antic pagus del comtat de Girona entregat de manera temporal a Radulf, una divisió ad hoc que no tenia per què sobreviure'l. Més amunt, d'esquitllada, hem comentat que els comtats de Barcelona, Girona i Osona van passar a mans de Sunyer I cap al 911, el qual estava sota la tutela del seu germà gran Guifré II. Amb tot, si no hagués estat en virtut d'aquesta tutela, que es va traduir en una associació de Sunyer al poder, els comtats de Guifré II potser haurien d'haver recaigut en el segon fill del Pelós, Miró II de Cerdanya. Entre els anys 910 i 920, en el si dels comtats catalans es va haver de dirimir si Sunyer I havia de governar Barcelona, Girona i Osona i si el comtat de Besalú havia de tornar a formar part del comtat de Girona, en virtut de l'antiga unió. Sembla que Miró II no va oposar-se a la successió del seu germà petit Sunyer com a sobirà barceloní, i sembla que inicialment Sunyer no s'oposà al fet que Besalú es deslligués de Girona i passés a mans del casal de Cerdanya. Podríem pensar, doncs, que les parts van arribar a un acord: a canvi de la renúncia als possibles drets d'herència de Miró II sobre Barcelona, Osona i Girona, Besalú passava a formar part de les propietats

\footnotetext{
${ }^{41}$ Marca, Baluze 1688, col. 389.
} 
de Cerdanya. Cal tenir present també que amb la transferència de Besalú el territori del Ripollès s'amputava d'Osona i passava a Miró II ${ }^{42}$.

Al cap de poc temps, quan Sunyer havia consolidat la seva posició com a comte i quan Cerdanya passava per un període de regència dirigit per la comtessa Ava, l'ambició del comte de Barcelona va començar a fixar-se als territoris cedits uns anys abans, ambició que va suposar les tensions que més amunt esmentàvem entre els casals de Barcelona i Cerdanya. Ara bé, com hem dit, és força improbable que aquestes derivessin en una batalla a Baltarga a principis de la dècada dels quaranta, tant pel context polític del moment com per la situació geogràfica de la localitat cerdana. El que realment va provocar l'enfrontament obert i la batalla a començaments dels anys quaranta del segle $\mathrm{X}$ va ser, no només la sobirania d'aquests territoris, sinó la successió del comtat d'Urgell després de la mort de Sunifred II cap al 940.

En uns anys en què el traspàs de la sobirania a través de la successió no estava prou clar ni consolidat, tampoc estava clar a mans de qui havia de recaure l'herència urgellenca. Hem vist com el pacte de repartiment i les preferències personals de cada comte són raons de més pes a l'hora de repartir les propietats que no pas una lògica successòria no instaurada. Hom podria dir que si Sunyer I era l'últim comte viu fill de Guifré el Pelós a ell li pertocava governar Urgell. També es podria adduir, però, que Cerdanya i Urgell havien estat dues entitats territorials tradicionalment unides i, que per tant, pertocava als comtes de Cerdanya de governar aquell territori ${ }^{43}$. De fet, aquest era l'argument que feia servir Sunyer I quan reclamava Besalú. A més, els fills de Miró II sabien que el seu pare havia renunciat a l'herència barcelonina que potser li pertocava; per què ara havien de renunciar també a Urgell si com a descendents de Guifré hi tenien els mateixos drets que Sunyer?

La successió de Sunifred II d'Urgell, a principis dels anys quaranta de la desena centúria, amenaçava de convertir-se en un atzucac polític que només es podia resoldre amb un cop d'efecte. Aquest cop d'efecte finalment es va produir a Baltarga i va tenir tràgiques conseqüències per a un dels candidats a esdevenir comte d'Urgell: Ermengol d'Osona.

\section{ERMENGOL D'OSONA, PRIMOGÈNIT DE SUNYER I, COMTE D'URGELL}

Sunyer I va associar el seu primogènit al poder en terres osonenques a la fi de la dècada de 930. El 936 trobem pare i fill actuant junts en la venda

\footnotetext{
${ }^{42}$ Salrach 1973, p. 7.

${ }^{43}$ Coll 1992, p. 197.
} 
d'unes propietats als comtats de Besalú, Girona, Manresa i Osona ${ }^{44}$. Tres anys més tard, ambdós comtes van fer consagrar al bisbe Jordi de Vic l'església de Santa Maria de Moiàa ${ }^{45}$. A diferència de l'any 936, en aquesta ocasió Ermengol és anomenat Ausonensis comes, fet que ens indica que el jove hauria estat associat al poder perquè governés aquell comtat. Després del 23 d'agost del 939 ja no sabem res més d'Ermengol d'Osona fins als anys 943 i 945 quan els seus pares, Sunyer i Riquilda, fan diverses donacions per a la salvació de la seva ànima ${ }^{46}$.

Pensem que Sunyer va associar Ermengol al govern d'Osona i no al d'un altre comtat per les disputes familiars que s'estaven gestant en aquell moment. Malgrat que el risc de les tensions entre els casals de Cerdanya i Barcelona difícilment haurien degenerat, a curt termini, en una gran guerra oberta, Sunyer volia tenir controlats els seus dominis septentrionals, sobretot els limítrofs amb Besalú i Cerdanya al Ripollès. Posar el seu plançó al capdavant del govern d'Osona li assegurava un major control de la situació. A més a més, Sunyer tampoc hauria situat un jove i inexpert Ermengol en dominis de frontera on les algarades musulmanes, tot i la situació de pau que es va assolir cap a l'any 940 , haurien pogut tenir conseqüències territorials, polítiques i econòmiques molt negatives.

La situació tibant entre Sunyer I i els seus nebots de Cerdanya va explotar definitivament a la mort de Sunifred II d'Urgell, òbit que degué produir-se cap al 940. L'any següent, com hem vist, la comtessa Adelaida actuava tota sola com a sobirana d'Urgell, però era evident que aquella situació no podia perllongar-se gaire temps si el matrimoni no havia tingut descendència $i$, per tant, si la comtessa no actuava de regent temporal ${ }^{47}$. És en aquesta conjuntura que segurament Sunyer i Ermengol van decidir de fer-se amb el control de les terres urgellenques fins al punt que podem pensar, tot i que de manera hipotètica, que Ermengol va esdevenir comte d'Urgell associat al seu pare, que governava els nuclis principals de Barcelona i Girona ${ }^{48}$. Per a Sunifred II de Cerdanya -cal evitar confondre'l amb el seu oncle urgellenc- i els seus germans això era gairebé una declaració de guerra, fet que va obrir la caixa dels trons.

${ }^{44}$ Ordeig 1999, doc. 420.

${ }^{45}$ Ibidem, doc. 464.

${ }^{46} \mathrm{Ibidem}$, doc. 535,539 i 551.

${ }^{47}$ Hom ha parlat de la possibilitat que Sunifred II i Adelaida haguessin tingut un fill, Borrell, mort abans que els seus pares (entre d'altres, Bofarull 1836, p. 70). Nosaltres creiem que les proves presentades són, si més no, dubtoses. Sigui com sigui, l'òbit d'aquest possible fill abans que la dels seus pares no altera la situació urgellenca a principis del 940.

${ }^{48}$ Hipòtesi formulada per Martí 2013, p. 84 


\section{LA BATALLA DE BALTARGA, LES USURPACIONS SOBRE SANT JOAN DE LES ABADESSES I LA INCURSIÓ A LA VALL DE LORD (941-947)}

L'esclat dels conflicte entre els successors del Pelós el tenim documentat per tres episodis diferents: l'esmentada batalla de Baltarga, l'intent d'usurpació de propietats de Sant Joan de les Abadesses per part de Sunyer I i l'atac sobre la vall de Lord, en territori urgellenc, per part de Sunifred II de Cerdanya. Malgrat que no puguem escatir la data de cada un d'aquests esdeveniments, sí que sabem que els tres es van produir entre el 940 i el 948, és a dir, entre la mort de Sunifred II d'Urgell i el retir de Sunyer I de Barcelona al monestir de la Grassa. Aquesta manca d'informació ens fa difícil de situar cronològicament els diversos fets $\mathrm{i}$, per tant, els presentarem simplement com a contemporanis. El que sí que creiem és que el moment culminant d'aquest conflicte va ser la batalla de Baltarga, les consequiències de la qual haurien marcat un abans i un després.

Com hem esmentat en diverses ocasions, la possessió del Ripollès estava en disputa. En aquell territori s'hi concentraven dos importants monestirs, Santa Maria de Ripoll i Sant Joan de les Abadesses. Ambdós havien estat fundacions de Guifré I i de Sant Joan la filla del comte fundador, Emma, n'era l'abadessa (897-942). Alguns historiadors apunten que entre Emma i el seu germà Sunyer I havien sorgit algunes tensions per determinats dominis del monestir ${ }^{49}$. No va ser fins a la mort d'Emma, però, que Sunyer va poder atacar amb llibertat les propietats del cenobi, fins al punt que entre el $942 \mathrm{i}$ el 949 una abadessa, de nom desconegut i gens capacitada per a la tasca, va regir el monestir ${ }^{50}$. Aquesta abadessa, sense cap mena de dubte, va ser elegida per Sunyer per afavorir els interessos del casal de Barcelona. Tenint en compte els extensos dominis d'aquest monestir protegit i patrocinat pels comtes, Sunyer aconseguia que part del Ripollès estigués directament sota el seu control en detriment dels comtes de Cerdanya.

Per la seva banda, Sunifred II de Cerdanya, potser amb la voluntat d'aconseguir el control del comtat d'Urgell, va penetrar a la vall de Lord en un moment indeterminat d'aquells anys. Ho sabem gràcies a un capbreu de les parròquies de la vall en qüestió en el qual es diu que el comte Sunifred va usurpar la propietat de diverses esglésies ${ }^{51}$. Hom ha emprat aquest document per retardar la mort de Sunifred II d'Urgell fins al 948, però el comte Sunifred

\footnotetext{
${ }^{49}$ Coll 1992, p. 196.

${ }^{50}$ La informació prové del document de nomenament d'Adelaida com abadessa de Sant Joan l'any 949 (Udina 1951, doc. 128).

${ }^{51}$ Villanueva 1821, ap. 13.
} 
al qual es refereix és el de Cerdanya, no pas el d'Urgell ${ }^{52}$. Sunifred d'Urgell ja havia mort i seria d'allò més estrany que després de gairebé cinquanta anys en el càrrec es decidís, al final de la seva vida, a usurpar parròquies del bisbat d'Urgell. Si situem l'episodi en el si dels conflictes per la successió del comtat d'Urgell entre els casals de Cerdanya i Barcelona, l'episodi de Lord s'entén perfectament, ja que és un territori limítrof amb el comtat de Berga, a mans de Sunifred II de Cerdanya.

Per tant, mentre uns controlaven el Ripollès fent-se seves propietats de Sant Joan de les Abadesses, els altres feien el mateix amb la vall de Lord. És en aquesta conjuntura que la batalla de Baltarga pren el seu sentit històric. Gairebé en una mena d'ordalia, forces barcelonines -probablement des d'Urgell- i cerdanes es van enfrontar directament en una batalla que havia de decidir, fonamentalment, la successió del comtat d'Urgell. Cap dels dos blocs familiars hi volia renunciar. Sunyer ja havia perdut Besalú i no podia deixar escapar la possibilitat de governar Urgell. El seu nebot Sunifred, tot i la seva joventut, sabia que ell també tenia drets sobre aquell territori i la seva renúncia hauria atorgat un poder massa gran a Sunyer i Ermengol, que s'haurien convertit en senyors de Barcelona, Girona, Osona i Urgell i encara amb pretensions sobre Besalú. Per entendre la por del casal de Cerdanya només cal fixar-se en el beneficiari de tot aquest ball territorial de mitjan segle X, Borrell II, un comte que va governar una basta extensió de territori i que va tenir sota el seu poder quatre seus episcopals (mentre que el seu cosí Oliba Cabreta de Cerdanya no en tenia cap), el gairebé monopoli de les relacions amb el califat de Còrdova i fins i tot va intentar de capitalitzar un arquebisbat català en més d'una ocasiós ${ }^{53}$.

No sabrem mai el nombre de guerrers que van lluitar a Baltarga ni tampoc si va ser un enfrontament relativament important o bé un conflicte més discret. Tampoc sabrem si Sunyer I o Sunifred II hi van ser o si Ermengol fou l'únic comte que hi lluità. El que sí que sabem és que Ermengaudus (...) apud Baltargam bello interfectus, sine filio obiit, et sepultus est in monsaterio Rivipullense $^{54}$. Ara bé, tot i la mort del jove comte, la victòria final, ja fos a Baltarga o a través d'algun acord posterior, va acabar sent per al casal de Barcelona. A partir de mitjan segle X, Borrell II, segon fill de Sunyer i germà del difunt Ermengol, actuava com a comte d'Urgell.

La batalla de Baltarga devia produir-se el 21 o el 22 d'agost dels anys 941,942 o 943. L'última notícia d'Ermengol d'Osona en vida és del 939,

\footnotetext{
${ }^{52}$ Devem aquesta informació al Dr. Ramon Martí, a qui agraïm el comentari.

${ }^{53}$ Martí 1993,pp. 369-386.

${ }^{54}$ Cingolani 2012, p. 127.
} 
però a la primavera del 941 la comtessa vídua Adelaida encara s'intitulava comtessa d'Urgell i per tant semblaria que el conflicte encara no hauria esclatat, com a mínim obertament. Aquesta suposició ens obliga a retardar la data de la batalla als anys 941-943. Com hem apuntat, creiem que la batalla de Baltarga va marcar un abans i un després del conflicte en gran mesura per la tràgica mort d'Ermengol, succés que hauria fet repensar als contendents si realment la guerra oberta entre uns i altres era la solució. Per tant, abans de la batalla hi hauria hagut una escalada de tensions detectable en els episodis que hem anat desgranant. Això obligaria a considerar que la contesa de Baltarga es va produir després de les usurpacions barcelonines a Sant Joan posteriors a la mort de l'abadessa Emma, és a dir, després del 8 de novembre de $942^{55}$. Si segons els necrologis la mort d'Ermengol es va produir un 21 o 22 d'agost, aquesta només podria ser de l'any 943 . Creiem, doncs, com a hipòtesi no definitiva, que la batalla es devia produir el 21 o el 22 d'agost del 943. En aquesta, Ermengol d'Osona hi perdé la vida i el seu fèretre fou dut a Ripoll, on va ser enterrat $\mathrm{i}$ on el seu pare Sunyer I va fer donacions per la seva ànima pocs dies després, el 6 de setembre del 943.

\section{LA FI DEL CONFLICTE}

És evident que en tot conflicte bèl-lic la mort és un company de viatge dels guerrers que hi participen. Ara bé, tot i tractar-se d'un conflicte obert, no creiem que les cases comtals de Barcelona i Cerdanya tinguessin la intenció d'anihilar-se entre si. Creiem que la mort d'Ermengol d'Osona va ser una consequiència no esperada del conflicte, ja que immediatament després del tràgic succés els bàndols enfrontats van decidir buscar l'acord.

L'estiu del 949 era elegida Adelaida com a abadessa del monestir de Sant Joan. Segons el document de nomenament, a la mort d'Emma, Sunyer, portat per l'ambició (cupiditate ductus), elegí per al càrrec d'abadessa un persona no preparada ${ }^{56}$. Conscient del seu error, però, el comte volgué rectificar a través del seu fill Borrell II, d'aquí el nomenament en qüestió, mentre ell prenia els hàbits de la religió. L'elecció d'una nova abadessa per Sant Joan fou segurament un dels punts d'acord a què arribaren les dues parts per acabar amb el conflicte. D'altra banda, pel capbreu de parròquies de la vall de Lord abans mencionat sabem que el 948 ja no estaven en mans del comte Sunifred II

\footnotetext{
${ }_{55}^{55}$ Ordeig 1999, doc. 521.

${ }^{56}$ Udina 1951, doc. 128
} 
de Cerdanya ${ }^{57}$. El comte de Cerdanya segurament havia retornat la vall al comtat d'Urgell, renunciant d'aquesta manera als possibles drets de successió que podia tenir sobre el comtat del seu oncle. Això ens fa pensar que si bé Ermengol d'Osona morí a Baltarga, els interessos barcelonins van acabar imposant-se sobre els de Cerdanya i, per tant, la batalla s'hauria decantat a favor dels objectius de Sunyer I.

D'altra banda, sembla que el comtat de Besalú, també cobejat en algun moment per Sunyer, deixà de ser objecte de polèmica a partir d'aquest moment. A partir del 945, Guifré, fill de Miró II i Ava, va començar a governar-lo sense que documentem conflictes amb els seus parents, uns conflictes que sí que es reproduiran de nou anys més tard ${ }^{58}$. Per tant, la successió urgellenca a favor de Borrell II s'hauria acordat a través de la renúncia barcelonina als interessos sobre Besalú i les zones del Ripollès dependents de Sant Joan de les Abadesses. Cal tenir en compte, també, que en una data indeterminada entre el 940 i el 952 els comtes de Cerdanya van patir la revolta del vescomte Unifred. La revolta no sembla tenir relació directa amb el nostre objecte d'estudi però segur que va actuar d'element desestabilitzador i en cas d'haverse produït en els mateixos anys que el conflicte per la successió del comtat d'Urgell hauria estat un element més que hauria fet decantar Sunifred II de Cerdanya per l'acord i no per mantenir una guerra a dues bandes ${ }^{59}$.

\section{L'EPITAFI D'ERMENGOL D'OSONA I EL RETIR DE SUNYER I}

Hic Ermengaudus, Sunieri nobile pignus, perditus, heu, gladio, ac, requiescit humo, hunc fera mors rapuit, quae nulli parcere nouit: parce, Deus, famulo, conditor alme, tuo ${ }^{60}$.

[Aquí Ermengol, noble penyora de Sunyer, perdut per l'espasa, ai, descansa enterrat, l'arrabassà la fera mort, que no respecta a ningú, oh Déu, creador benèvol, apiada't del teu servidor] ${ }^{61}$.

Aquestes són les paraules que l'abat Oliba de Ripoll i de Cuixà i bisbe de Vic va dedicar a Ermengol d'Osona. En cap cas són els versos dedicats a un

\footnotetext{
${ }^{57}$ Villanueva 1821 , ap. 13.

${ }^{58}$ Salrach 1973, p. 11.

${ }^{59}$ Ibidem, p. 8.

${ }^{60}$ Martínez Gázquez, Florio 2006, p. 245.

${ }^{61}$ Traducció de la Dra. Cándida Ferrero, a qui agraïm la seva col-laboració i els seus encertats comentaris en relació amb aquest epitafi.
} 
comte mort lluitant contra pagans infidels, més aviat és un epitafi lúgubre d'una persona morta per una espasa familiar. Tant aquest epitafi com la notícia de les Gesta semblen voler amagar la tragèdia d'una mort trista pel fet d'haver-se produît en el si d'una mateixa família, la dels descendents de Guifré el Pelós.

La mort del seu primogènit sembla que colpí durament Sunyer I el qual havia estat, en gran mesura, l'instigador del conflicte. Sentint-se culpable, va intentar d'arranjar les decisions que la seva consciència considerava incorrectes i optà per acabar els seus dies en el retir espiritual de Santa Maria de la Grassa, entre Narbona i Carcassona. Borrell II, el seu segon fill, va acabar de tancar els assumptes pendents del seu pare i es va erigir en el comte que havia d'haver estat Ermengol, senyor de Barcelona, Osona, Girona i Urgell. Malgrat que amagat rere una pàtina de tristesa, el record del jove comte d'Osona perdurà fins al punt que Borrell II batejà amb el nom d'Ermengol al seu segon fill, justament el plançó que havia de fer-se càrrec, al cap d'uns anys, del comtat d'Urgell (c. 990 - 1010). Així doncs, gairebé cinquanta anys després de la batalla de Baltarga per la successió del comtat d'Urgell, un Ermengol va acabar governant el comtat pirinenc.

\section{CONCLUSIÓ}

La batalla de Baltarga, sovint considerada un xoc entre forces comtals catalanes i hordes hongareses, va ser un enfrontament intern de la política comtal catalana del segle $\mathrm{X}$ motivat, principalment, per la successió del comtat d'Urgell. En efecte, a la mort de l'urgellenc Sunifred II, mort que hem de situar cap al 940, les cases comtals de Barcelona i Cerdanya, descendents directes de Guifré el Pelós, van disputar-se la sobirania del comtat d'Urgell. Les conseqüències d'aquesta disputa van ser tràgiques, ja que el primogènit de Sunyer I de Barcelona, Ermengol d'Osona, va perdre la vida a la localitat cerdana de Baltarga a mans de les hosts del seu cosí Sunifred II de Cerdanya, segurament el 21 o el 22 d'agost del 943 . El conflicte entre ambdues cases comtals feia alguns anys que s'estava gestant per raó de la successió del comtat de Barcelona a la mort de Guifré II (911), successió que potser hauria d'haver recaigut en Miró II de Cerdanya, i en la separació definitiva del pagus de Besalú del comtat de Girona, una divisió que va allunyar aquest comtat del domini barceloní. Des del primer terç del segle X, per tant, cerdans i barcelonins van viure situacions de tensió que es van acabar traduint en un conflicte obert a la dècada dels quaranta. Les usurpacions de terres del monestir de Sant Joan de les Abadesses per part de Sunyer I, la invasió de la urgellenca vall de Lord dirigida per Sunifred II de Cerdanya i la batalla de Baltarga entre barcelonins i cerdans van ser els punts àlgids d'aquest conflicte. 
La mort d'Ermengol d'Osona a Baltarga, tot i la victòria dels interessos barcelonins, va suposar un cop molt fort per a Sunyer I i fins i tot per als seus parents cerdans. Conscients que s'estava anant massa lluny i que les consequiències d'una guerra intestina podrien ser fatals per a tots, les dues parts van buscar un acord per arranjar la situació. El comtat d'Urgell finalment va passar a mans barcelonines, mentre que Sunyer I segurament va renunciar als seus interessos sobre el Ripollès i Besalú. L'abandó de la vida temporal per part de Sunyer, afectat probablement per la mort del seu primogènit, va facilitar l'entesa entre els néts de Guifré el Pelós, Borrell II de Barcelona-Urgell i Sunifred II de Cerdanya-Besalú. Amb tot, la pau no fou definitiva als comtats i pocs anys després el conflicte entre ambdues cases comtals va obrir-se de nou.

Aquest conflicte d'interessos en el si dels comtats catalans al segle $\mathrm{X}$ no sembla una situació excepcional, ans al contrari. Des de dues perspectives diferents, J.E. Ruiz-Domènec i R. Martí han destacat en els últims anys que les desavinences entre les cases comtals de Barcelona i Cerdanya van continues al llarg de la segona meitat del segle X i la primera de l'XI. Aquest fet, a parer seu, obliga a replantejar el paradigma d'Abadal, encara vigent en gran mesura, que veia en aquests anys una trajectòria convergent dels comtats catalans que havia de culminar en l'edificació de Catalunya ${ }^{62}$. Altres historiadors, com el repetidament citat Coll i Alentorn, ja van detectar aquesta conflictivitat interna, com en el cas aquí estudiat, però la historiografia catalana actual encara no ha estat capaç de replantejar els paradigmes dels clàssics per tal de poder interpretar i entendre satisfactòriament els comtats catalans de fa mil anys. A parer nostre, seguint l'estela de Ruiz-Domènec, de Martí i d'altres, creiem que cal rehistoriar la marxa a la sobirania des d'un nou prisma historiogràfic capaç d'explicar les diverses posicions de les cases comtals catalanes en el que podem anomenar la construcció de la Catalunya medieval.

\section{BIBLIOGRAFIA CITADA}

Abadal, Ramon d' (2011), Els primers comtes catalans, Barcelona, La Magrana.

Baraut, Cebrià (1979), Els documents, dels segles IX $i$ X, conservats a l'Arxiu Capitular de la Seu d'Urgell, "Urgellia" 2, pp. 7-146.

Baraut, Cebrià (1983), Els documents, dels anys, 1051-1075, de l'Arxiu Capitular de la Seu d'Urgell, "Urgellia" 6, pp. 7-244.

${ }^{62}$ Martí 1993,p. 382; Ruiz-Domènec 2006; 2010 
Baraut, Cebrià (1986), Les actes de consagracions d'esglésies de l'antic bisbat d'Urgell (segles IX-XII), La Seu d'Urgell, Societat Cultural Urgel-litana.

Benet, Albert (1982a), La incursió d'hongaresos a Catalunya l'any 942, "Quaderns d'Estudis Medievals" 9, pp. 568-574.

Benet, Albert (1982b), La batalla de Balltarga. Epíleg de la incursió d'hongaresos a Catalunya l'any 942, "Quaderns d'Estudis Medievals" 10, pp. 639-640.

Blasi, Joan (1999), Els oblidats comtes de Cerdanya (798-1117), Sant Vicenç de Castallet, El Farell.

Bofarull, Pròsper de (1836), Los Condes de Barcelona vindicados, Barcelona, Impr. de J. Oliveres y Monmany.

Bramon, Dolors (2000), De quan érem o no musulmans, Vic, Eumo.

Cingolani, Stefano (ed.) (2012), Les Gesta Comitum Barchinonensium (versió primitiva), la Brevis Historia $i$ altres textos de Ripoll, València, Universitat de València.

Coll, Miquel (1992), Història/2, Barcelona, Curial.

Fluvià, Armand de (1989), Els primitius comtats $i$ vescomtats de Catalunya, Barcelona, Enciclopèdia Catalana.

Flórez, Enrique (1774), España Sagrada, vol. XXVIII, Madrid, A. de Sancha. Flórez, Enrique (1819), España Sagrada, vol. XLIII, Madrid, Imprenta de Collado.

Junyent, Eduard (1962), El necrologi del monestir de Ripoll, "Analecta Montserratensia" 9, pp. 217-225.

Marca, Pierre de; Baluze, Étienne, (1688), Marca Hispanica sive limes hispanicus, París, apud Franciscum Muguet,.

Martí, Ramon (1993), Delà, Cesari i Ató, primers arquebisbes dels comtesprínceps de Barcelona (951-953/981), a I Congrés d'Història de l'Església Catalana des dels orígens fins ara, Solsona.

Martí, Ramon (2013), Población y reorganización del territorio: castillos, parroquias y sagreres a Enciclopedia del románico en Cataluña, Aguilar de Campoo, Fundación Santa Maria la Real-Aguilar del Campo, Centro de estudios sobre el Románico, pp. 67-86.

Martínez Gázquez, José; Florio, Rubén (coord.) (2006), Antología del Latín Cristiano y Medieval, Argentina, Universidad Nacional del Sur - Bellaterra, Universitat Autònoma de Barcelona.

Millàs, Josep Maria (1963), Sobre las incursiones húngaras en la Cataluña Condal, a Homenaje a Johannes Vincke para el 11 de mayo de 1962, Madrid, Consejo Superior de Investigaciones Centíficas - Goerres, Gesellshaft Zur Pflege Der Wissenshaft, vol. I, pp. 73-80. 
Ordeig, Ramon (1999), Catalunya Carolíngia. IV. Els comtats d'Osona $i$ Manresa, Barcelona, Institut d'Estudis Catalans.

Pladevall, Antoni (dir.) (1995), Catalunya Romànica, vol. VII, La Cerdanya El Conflent, Barcelona, Edicions 62.

Ruiz-Domènec, José Enrique (2006), L'abat Oliba: un home de pau en temps de guerra, "Butlletí de la Reial Acadèmia de Bones Lletres" 50, pp. 59-75.

Ruiz-Domènec, José Enrique (2010), Descobrint Oliba, "Revista de Dret Històric Catală" 10, pp. 105-121.

Sabaté, Flocel (2009), Catalunya Medieval, a Balcells, Albert (dir.), Història de Catalunya, Barcelona, L'Esfera dels llibres, pp. 99-334.

Salrach, Josep Maria (1973), El Comte Guifré de Besalú i la revolta de 957. Contribució a l'estudi de la Noblesa Catalana del segle X, a II Assemblea d'Estudis sobre el comtat de Besalú. Actes, Besalú, Amics de Besalú, pp. 3-38.

Sobrequés, Jaume; Morales, Mercè (2011), Comtes, Reis, Comtesses i Reines de Catalunya, Barcelona, Editorial Base.

Udina, Frederic (1951), El Archivo Condal de Barcelona en los siglos IX-X, Barcelona, Consejo Superior de Investigaciones Científicas.

Villanueva, Jaime (1821), Viage literario a las iglésias de España, vol. X, València, [s.n.].

Fecha de recepción del artículo: septiembre 2015

Fecha de aceptación y versión final: junio 2016 